\title{
Interleukin 15 augments antitumor activity of cytokine gene-modified melanoma cell vaccines in a murine model
}

\author{
GRZEGORZ W. BASAK ${ }^{1,2}$, LUKASZ ZAPALA ${ }^{1}$, PIOTR J. WYSOCKI ${ }^{3}$, \\ ANDRZEJ MACKIEWICZ ${ }^{3}$, MAREK JAKÓBISIAK ${ }^{1}$ and WITOLD LASEK ${ }^{1}$ \\ ${ }^{1}$ Department of Immunology, Centre of Biostructure Research, Medical University of Warsaw; \\ ${ }^{2}$ Department of Hematology, Oncology and Internal Medicine, Medical University of Warsaw, \\ Warsaw; ${ }^{3}$ Department of Cancer Immunology, University of Medical Sciences \\ at Great Poland Cancer Centre, Poznan, Poland
}

Received December 12, 2007; Accepted January 25, 2008

\begin{abstract}
Many studies have demnstrated that interleukin 15 (IL-15) is a cytokine with strong antitumor properties and have suggested its potential use in tumor immunotherapy. IL-15 exerts its effect on innate and acquired immunity with the most prominent action in $\mathrm{NK}$ cells and $\mathrm{CD} 8^{+}$memory $\mathrm{T}$ cells. Therefore, many authors have proposed that IL-15 could be a good candidate for augmenting the efficacy of vaccination strategies. In our experiments, in a model of B78-H1 murine transplantable melanoma, tumor-bearing mice were treated with different cytokine-gene modified tumor cell vaccines (producing TNF- $\alpha$, GM-CSF, IL-12 or IL-6/sIL-6R) followed by a series of IL-15 injections. In order to investigate the infiltration of treated tumors by leukocytes, immunohistochemical staining was performed. In every case, the combined therapy was superior to the treatment with either a vaccine or IL-15 alone. Tumors treated with the combination of B78-H1 melanoma cells secreting IL-12 (B78/IL-12 vaccine) and IL-15 were heavily infiltrated by granulocytes. IL-15, either alone or in combination with the B78/IL-12 vaccine, influenced infiltration of tumors with $\mathrm{CD}^{+}$lymphocytes, $\mathrm{CD}^{+}$and $\mathrm{CD}^{+}$. To our knowledge, this is the first report that shows the universal genetically-modified tumor cell vaccineaugmenting properties of IL-15. The cytokine can be useful as an adjuvant in cancer gene therapy in humans.
\end{abstract}

\section{Introduction}

Interleukin 15 (IL-15) was identified based on its ability to stimulate growth of the IL-2-dependent CTLL cell line in the

Correspondence to: Dr Witold Lasek, Department of Immunology, Centre of Biostructure Research, Medical University of Warsaw, Banacha 1a (F bldg), 02-097 Warsaw, Poland

E-mail:wlasek@ib.amwaw.edu.pl

Key words: interleukin 15, therapeutic tumor vaccines, immunotherapy absence of IL-2 (1). Consequently, it shares some biological functions of IL-2, since the two cytokines use the common receptor IL-2/15Rß $\gamma$. However, IL-15 uses the unique, highaffinity receptor IL-15R $\alpha$ and there is still growing evidence of its original and frequently opposing activities in comparison with IL-2. Notably, IL-15 seems to have stronger antitumor properties, although being significantly less toxic (2). IL-15 influences innate and acquired immune mechanisms. It is regarded as a physiological factor of NK cell maturation and activation, enhances their cytotoxicity and is critical for IFN- $\gamma$ secretion by NK cells (3-5). IL-15 is also an important factor in the differentiation of NKT cells (6).

On the other hand, IL-15 participates in the development of optimal adaptive $\mathrm{T}$ cell-mediated response. In contrary to IL-2, which is known to promote the activation of induced cell death (AICD), IL-15 inhibits apoptosis of activated T lymphocytes (7). IL-15 (though not IL-2) plays a dominant role in initiating $\mathrm{T}$ cell expansion in vivo (8) and acts chemotactically on them (9). IL-15 contributes to homeostatic proliferation (10) and survival of memory $\mathrm{CD}^{+} \mathrm{T}$ cells (11) and enhances their effector functions (12). Being a factor of dendritic cell activation (13), IL-15 contributes strongly to antigen presentation.

Based on these properties, IL-15 is used as an adjuvant in experimental immunotherapy of tumors and to increase the effectiveness of antimicrobial vaccines. IL-15 was found to be useful in the generation of LAK cells (14) and was exploited in adoptive immunotherapy (15) and in tumor gene therapy (16). Positive results of experiments, in which the effects of peptide-based anti-HIV vaccines (17), BCG vaccine (18), influenza and tetanus toxoid vaccines (19), prophylactically used antitumor dendritic cell-based vaccine (20), as well as results of our earlier studies encouraged us to examine whether IL-15 could potentiate antitumor effects of various cytokine-gene modified whole tumor cell vaccines.

\section{Materials and methods}

Mice. (C57BL/6xDBA/2)F1 mice, hereafter called B6D2F1, eight to twelve weeks of age, were used in the experiments. 
Mice were bred in a local animal facility and were kept in conventional conditions with full access to food and water during the experiments.

Tumor cells. The B78-H1 melanoma, weakly immunogenic amelanotic subclone of murine B16 melanoma cell line, was kindly provided by Dr L.H. Graf, Chicago, IL. Tumor cells were cultured in Dulbecco's MEM supplemented with $10 \%$ heat-inactivated FCS, antibiotics, 2-mercaptoethanol $(50 \mu \mathrm{M})$ and L-glutamine (2 mM) (all from Gibco BRL - Life Technologies Ltd, Paisley, UK) (DMEM culture medium). Cells were maintained in $25-\mathrm{cm}^{2}$ tissue flasks (Nunc, Roskilde, Denmark) at $37^{\circ} \mathrm{C}$ in a humidified atmosphere of $5 \% \mathrm{CO}_{2}$ and were passaged 2-3 times weekly.

Construction of retroviral vectors carrying the murine GMCSF , TNF- $\alpha, I L-6 /$ sIL-6R (hyper-IL-6) or IL-12 genes and generation of cytokine-expressing B78-H1 cells. The murine GM-CSF gene was excised from pGEMTeasy-mGM-CSF plasmid by digestion with NotI enzyme. The insert was cloned into DCCMV IRES Neo retroviral vector into the dephosphorylated NotI site. In the case of the IL-6 and sIL-6R genes, they were excised from adequate pCDM8/IL-6 or pCDM8/sIL-6R plasmids by the use of the SalI restriction enzyme and then cloned into DCCMV IRES Neo vector into the dephosphorylated SalI site. The construction of the retroviral vector carrying gene for human TNF- $\alpha$ or IL-12 was described previously (21).

Packaging cells PA317 (American Type Culture Collection, CRL 9078) were electroporated with vectors' cDNA suspended in PBS. Subsequently, these cells were plated and cultured in a culture medium [DMEM $+10 \%$ FCS + gentamicin $(0.08 \mathrm{mg} / \mathrm{ml})]$. Two days following the transfection, the cells were exposed to a selection medium containing geneticin (G418, Life Technologies Inc.) (1 mg/ $\mathrm{ml})$. Clones of cells resistant to the antibiotic were collected and screened for the production of recombinant retroviruses. For transduction purposes, a culture medium collected after $24 \mathrm{~h}$ of incubation from the vector-packaging cell culture (90\% of confluency) was used for the transduction of B78-H1. Shortly, B78-H1 cells were incubated in the infectious medium supplemented with polybrene $(4 \mu \mathrm{g} / \mathrm{ml})$ for $24 \mathrm{~h}$. Subsequently, the procedure was repeated and the cells were incubated in a selection medium (as described above). Tumor cells resistant to the selection were collected and, in the case of TNF- $\alpha$ or IL-12 transduced cells, cloned by a limited dilution technique. Preparation of B78-H1 melanoma cells producing a fusion protein consisting of IL- 6 and soluble receptor for this cytokine (sIL-6R), named B78/IL-6/ sIL-6R (hyper-IL-6), is described elsewhere (22). The amount of cytokines produced by the vaccine cells was: $8.1 \mathrm{ng} /$ $1 \times 10^{6}$ cells/ $24 \mathrm{~h}$ for TNF- $\alpha, 272 \mathrm{pg} / 1 \times 10^{6}$ cells $/ 24 \mathrm{~h}$ for IL-12, $551 \mathrm{pg} / 1 \times 10^{6}$ cells $/ 24 \mathrm{~h}$ for GM-CSF and $14.1 \mathrm{ng} / 1 \times 10^{6} \mathrm{cells} /$ $24 \mathrm{~h}$ for IL-6/sIL-6R.

$I L-15$. Recombinant human IL-15 (specific activity $4.96 \times 10^{5} \mathrm{U} / \mu \mathrm{g}$ protein) was kindly provided by Immunex Corp., Seattle, WA (now Amgen Inc.). This cytokine was diluted with $0.1 \%$ bovine serum albumin (BSA) (Sigma Chemicals, St. Louis, MO) in PBS for in vivo experiments.
Experimental procedure. B78-H1 melanoma cells were injected into the footpad of the right hind limb at the dose of $2 \times 10^{5}$ or $3 \times 10^{5}$ cells in $20 \mu 1$ PBS. On day 3 after tumor cell inoculation, mice were treated intratumorally with $1 \times 10^{6}$ viable cytokine-secreting B78-H1 cells (irradiated, 4500 rads). IL-15 was given at daily doses of $2 \mu \mathrm{g}$ in $20 \mu 10.1 \%$ BSA-PBS on days 6-10. Each injection of a vaccine or IL-15 was paralleled by i.t. injections of diluent into mice from the control groups. Local tumor growth was determined by measuring the diameter of the footpad (anterior-posterior dimension) with callipers every 3-4 days. Tumor size was calculated according to the formula: tumor diameter $=$ (diameter of footpad with growing tumor) - (diameter of non-treated contralateral footpad). The same therapeutic scheme was used in experiments involving different cytokine-gene modified tumor cell-based vaccines.

Immunohistochemical staining. For immunohistochemical analysis, mice were injected with $5 \times 10^{5}$ cells and treated with a vaccine containing IL-12-secreting melanoma cells and IL-15 as described above. One day after the last IL-15 injection, tumors were excised and immunohistochemical staining was performed as follows. Thin slices of tumors $(10 \mu \mathrm{m})$ were dehydrated in a mixture of methanol and acetone (ratio 1:1, $-20^{\circ} \mathrm{C}$ ). The internal activity of peroxidase was blocked by incubation in $3 \%$ oxygen peroxidase solution. In order to prevent the nonspecific binding of antibodies, samples were incubated for $30 \mathrm{~min}$ in $5 \%$ goat or donkey serum (Jackson ImmunoResearch), depending on the source of the secondary antibody. For staining, the following primary antibodies were used: 145-2C11 for CD3ع, CD8 for CD8a (Ly2), CD4 for CD4 (L3T4) (BD Bioscience), MCA497 for F4/80 (Serotec) and RB6-8C5 for Ly-6G (Gr-1, Gr1) (eBioscience). After overnight incubation with the primary antibodies (at $4-8^{\circ} \mathrm{C}$ ), secondary antibodies were used: Biotin-SP-conjugated AffiniPure donkey anti-rat IgG and Biotin-SP-conjugated AffiniPure goat anti-Armenian hamster IgG (Jackson ImmunoResearch). The immunohistochemical reaction was developed using $\mathrm{A}+\mathrm{B}$ reagent ( $\mathrm{ABC}$ kit, Vector Laboratories, $\mathrm{UK}$ ) and 3,3'-diaminobenzidine (DAB, Dako Cytomation, Denmark). The samples were stained with hematoxylin in accordance to the standard procedure.

Statistical analysis. The differences in tumor diameter were analysed for significance by the Student's t-test (two-tailed). To determine the difference in time to tumor appearance, the Kaplan-Meier analysis was performed employing the logrank test.

\section{Results}

Inhibition of tumor growth by genetically-modified vaccines in combination with $I L-15$. To evaluate the therapeutic activity of IL-15 in combination with therapeutic tumor vaccines, B78-H1 melanoma-bearing mice were treated i.t. with $1 \times 10^{6}$ live irradiated cytokine-secreting B78-H1 cells (on day 3 after inoculation of melanoma) and/or injected with $2 \mu \mathrm{g}$ IL-15 for five consecutive days, starting from day 6 . Four types of cytokine-secreting tumor vaccines were used: B78/TNF, B78/GM-CSF, B78/IL-6/sIL-6R and B78/IL-12. 

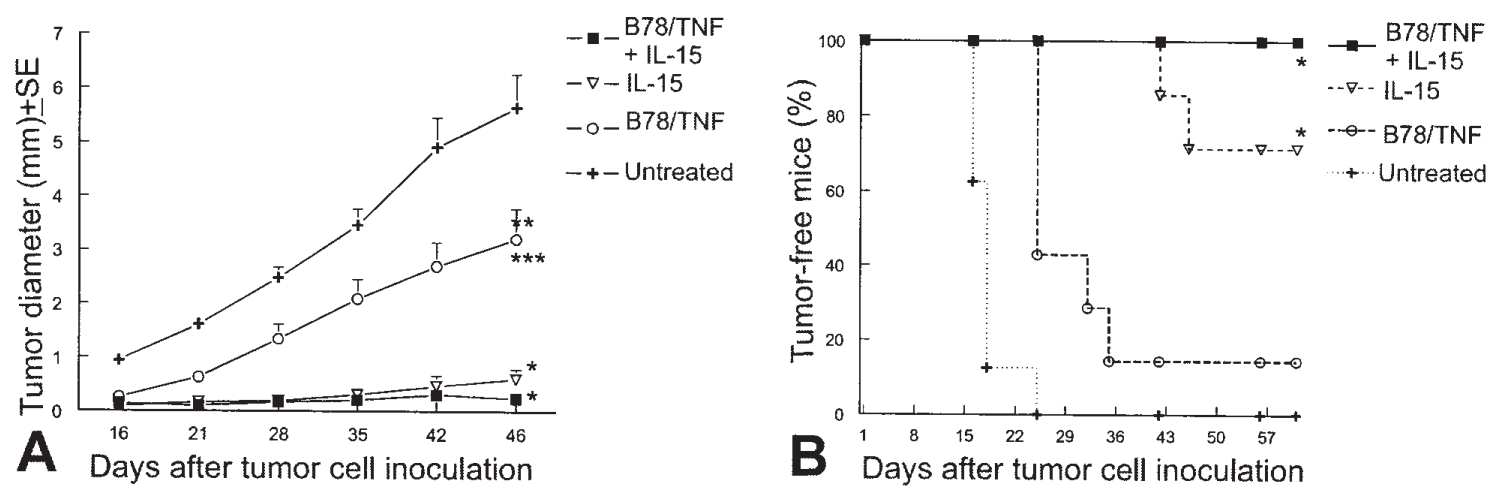

Figure 1. Therapeutic effects of the B78/TNF vaccine in combination with IL-15 on (A) tumor growth kinetics and (B) tumor-free index. ${ }^{*} \mathrm{P}<0.001 ;{ }^{* *} \mathrm{p}<0.05$ in comparison with the control group; ${ }^{* * *} \mathrm{p}<0.01$ in comparison with the combination-treated group.
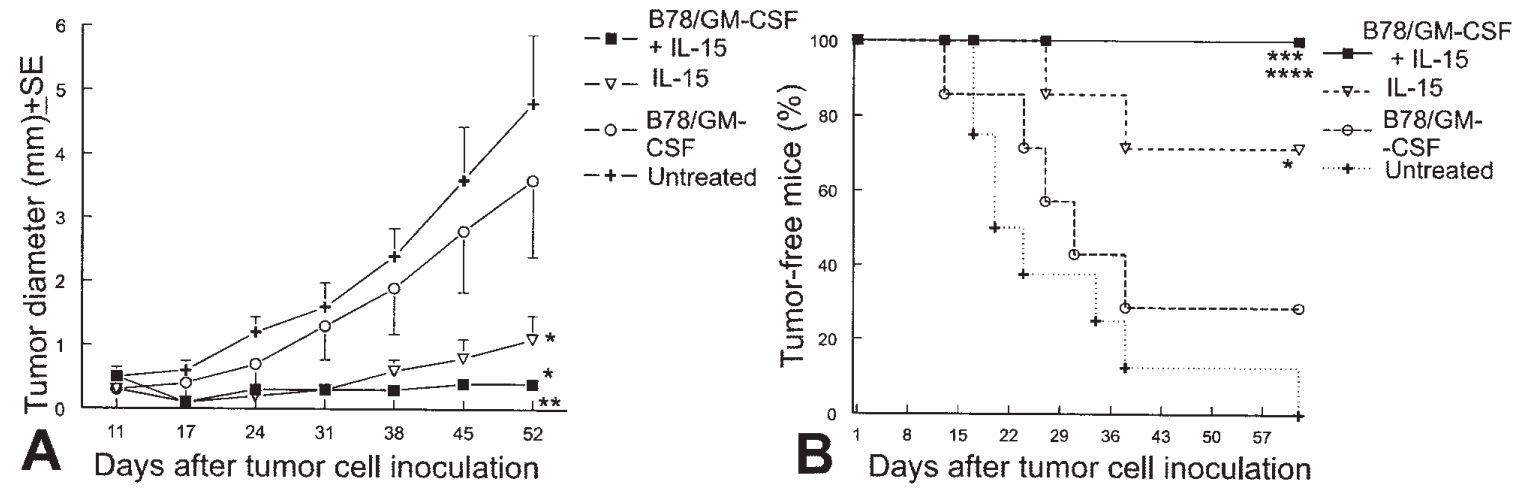

Figure 2. Therapeutic effects of the B78/GM-CSF vaccine in combination with IL-15 on (A) tumor growth kinetics and (B) tumor-free index. ${ }^{*} \mathrm{P}<0.01 ;{ }^{* * * *} \mathrm{p}<0.001$ in comparison with the control group; ${ }^{* *} \mathrm{p}<0.05 ;{ }^{* * * *} \mathrm{p}<0.01$ in comparison with the group treated with IL-15 alone.

The vaccine consisting of irradiated B78/TNF cells, IL-15 used alone, as well as the combination treatment induced significant inhibition of tumor growth in comparison with the untreated mice (day 46: $\mathrm{p}<0.05, \mathrm{p}<0.001$ and $\mathrm{p}<0.001$, respectively) (Fig. 1A). The therapeutic effect of the vaccine given alone was different from the untreated group and groups treated with IL-15 alone or in combination with the vaccine $(\mathrm{p}<0.01$, day 46). Similarly, the time to tumor appearance was significantly prolonged ( $\mathrm{p}<0.001$ for IL-15 and combination treatment and $\mathrm{p}<0.01$ for the vaccine alone). The combination treatment cured all the mice, whereas in the group treated with the B78/TNF vaccine alone, only $1 / 7$ mice was tumor-free (Fig. 1B).

The vaccine consisting of the B78/GM-CSF cells did not significantly influence either the tumor growth (Fig. 2A) or the time to tumor appearance (Fig. 2B), although it cured 2 out of 7 mice. In contrary, the combination treatment and IL-15 caused significant inhibition of tumor growth $(p<0.01$, day 52) in comparison with the control animals, though only the combined therapy with the B78/GM-CSF vaccine and IL-15 led to complete tumor regressions in each mouse. The effect of the combination treatment was significantly different from the vaccine-treated group ( $<<0.05$, day 52). Taking into account the time to tumor appearance, the results of IL-15 and combination therapy were significantly different in comparison to the untreated group $(p<0.001$ for the combination and $\mathrm{p}<0.01$ for IL-15 alone) but also in comparison to each other $(\mathrm{p}<0.01)$.

The therapy with the B78/IL-6/sIL-6R vaccine in combination with IL-15 remarkably inhibited tumor growth (Fig. 3A) in comparison with the animals treated with the vaccine alone $(\mathrm{p}<0.05$, day 49$)$ and untreated mice $(\mathrm{p}<0.01$, day 49). The vaccine B78/IL-6/sIL-6R used alone exhibited a low curative potential, although was statistically different from the control group ( $\mathrm{p}<0.05$, day 49). However, it did not cause any tumor regression and did not prolong the time to tumor appearance. The combination treatment with the B78/IL-6/sIL-6R vaccine and IL-15 cured 3/7 mice and significantly prolonged time to tumor appearance in comparison with the control group $(\mathrm{p}<0.01)$.

The combination of the B78/IL-12 vaccine and IL-15 cured all the mice (Fig. 4) $(\mathrm{p}<0.001$ in comparison to the untreated animals, day 49), whereas in groups treated with IL-15 or the vaccine alone, tumor outgrowth in $2 / 7$ or $4 / 7$ animals, respectively, was observed. Although the difference between these groups was not statistically significant, it seems that the combination was more effective than the treatment with single agents.

Immunohistochemical analysis of tumors treated with the combination of the B78/12 vaccine and IL-15. The immunohistochemical staining revealed a strong influence of IL-15 


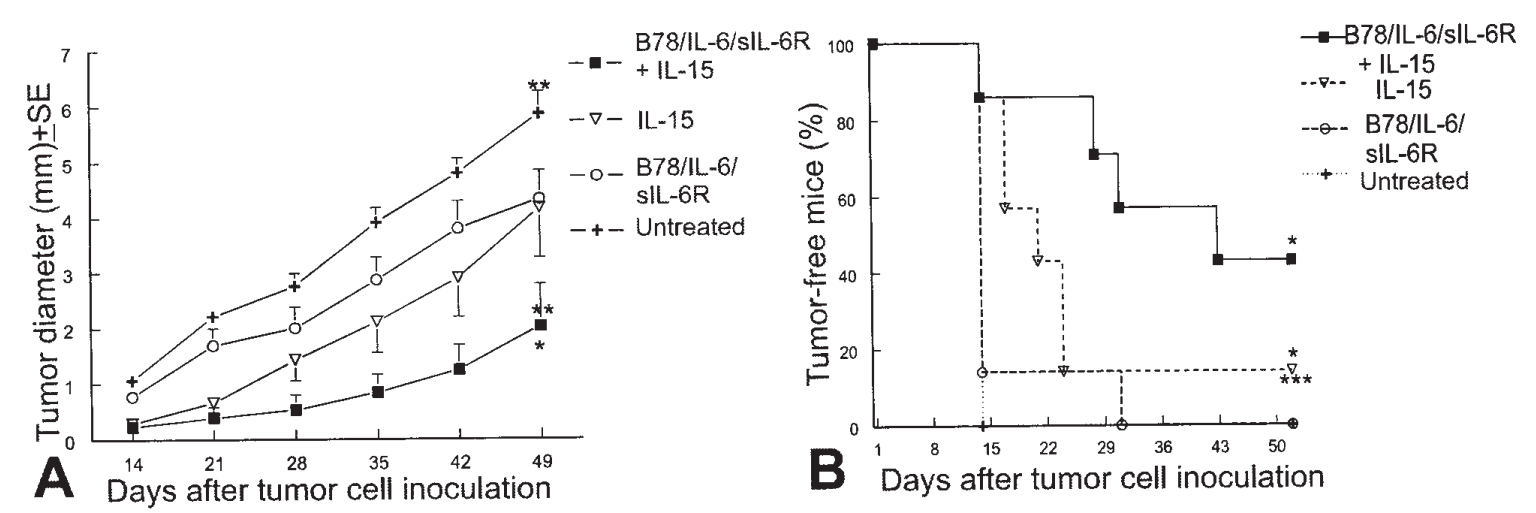

Figure 3. Therapeutic effects of the B78/IL-6/sIL-6R vaccine in combination with IL-15 on (A) tumor growth kinetics and (B) tumor-free index. ${ }^{* *} \mathrm{P}<0.05$ in comparison to the vaccine-treated group; ${ }^{* * *}$ N.S. in comparison with the combination-treated group.
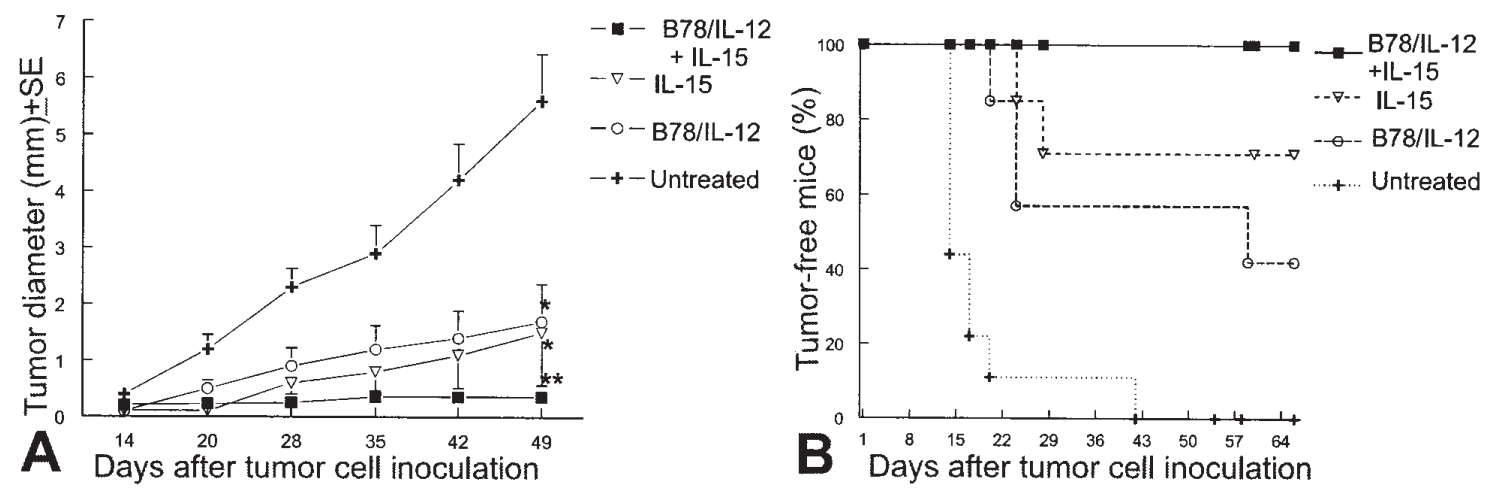

Figure 4. Therapeutic effects of the B78/IL-12 vaccine in combination with IL-15 on (A) tumor growth kinetics and (B) tumor-free index. ${ }^{*} \mathrm{P}<0.01$; ${ }^{* *} \mathrm{P}<0.001$ in comparison with the control group.

on tumor infiltration by CD3+ $\mathrm{T}$ lymphocytes (Fig. 5A-D). In contrary to the control group, where $\mathrm{T}$ lymphocytes were present mainly within connective tissue, in tumors from mice that underwent treatment with IL-15, lymphocytes were found among neoplastic cells. Staining of CD4 (Fig. 5E-H) and CD8 (Fig. 5I-L) molecules revealed that infiltrates consisted of $\mathrm{CD}^{+}$and $\mathrm{CD}^{+} \mathrm{T}$ lymphocytes at a similar ratio. Immunohistochemical staining of granulocytes (Ly-6G marker) revealed an evident effect of the combined treatment on tumor infiltration by these cells (Fig. 5M). In tumors treated with the combination therapy, there were massive focal infiltrates of granulocytes, whereas in tumors from other groups only single granulocytes were noted. The immunohistochemical staining of macrophages (Fig. 5R) revealed that B78-H1 tumors were markedly infiltrated by macrophages, independently on treatment.

\section{Discussion}

In the last decade, a significant progress in oncological care and the treatment of tumor patients has been made. Although chemotherapy and radiotherapy prolonged patient survival, the problems with their remarkable toxicity and lack of specificity account for the search for alternative treatment modalities. Immunotherapy may override traditional chemotherapy and radiotherapy limitations. Therapeutic tumor vaccines seem to be one of the most promising strategies in tumor immunotherapy.

Among different concepts of antitumor vaccination that exploit specific tumor antigens and dendritic cells, there is still clinical interest in the use of vaccines made of irradiated but live, whole tumor cells. They represent a whole spectrum of antigens characterising the tumor. This approach enables vaccination against tumors with uncharacterised epitopes and potentially protects against certain tumor escape mechanisms. However, in order to elicit an efficient immune response, vaccine antigens must be presented in a suitable microenvironment. Therefore, the vaccine cells are admixed with adjuvants or are genetically modified, generally with genes encoding appropriate cytokines. The locally secreted cytokine is then able to mount an efficient immunological response without systemic toxicity. A large number of preclinical and clinical reports dealing with cytokine genemodified tumor cell vaccines have already been published. However, despite a marked influence on immunological parameters, only a minor clinical response has been observed (23). Therefore, there is still a need to enhance the efficacy of this strategy.

In our previous study, we showed a strong beneficial effect of IL-15 administered in combination with IL-12 secreting the B78-H1 murine melanoma cell vaccine (B78/IL-12) (24). Whereas the administration of the B78/IL-12 


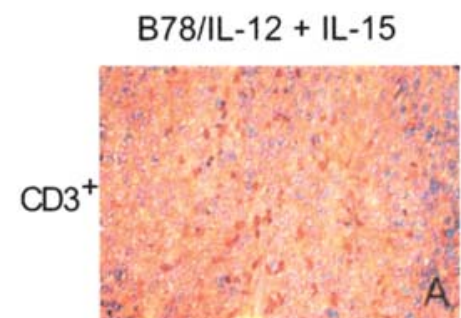

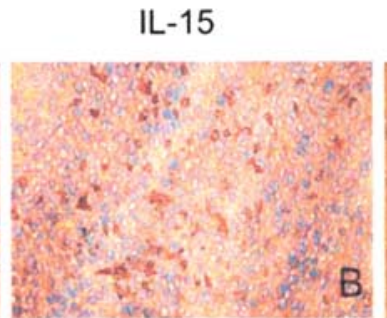

B78/IL-12
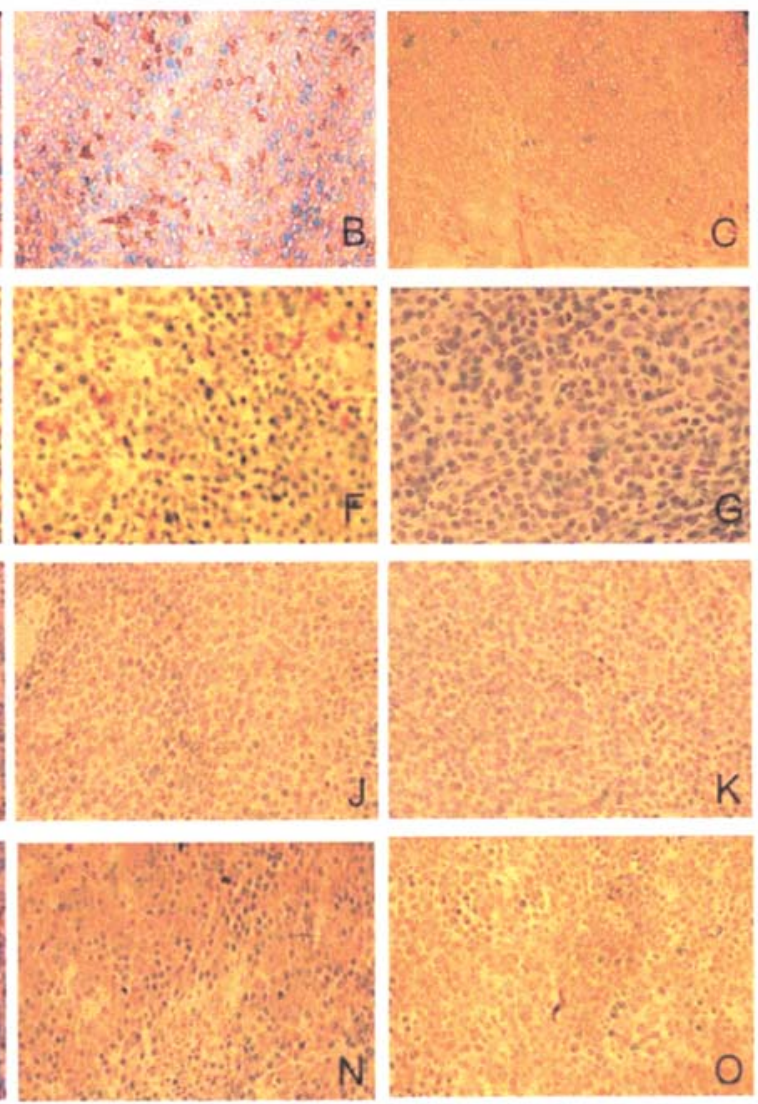

Untreated
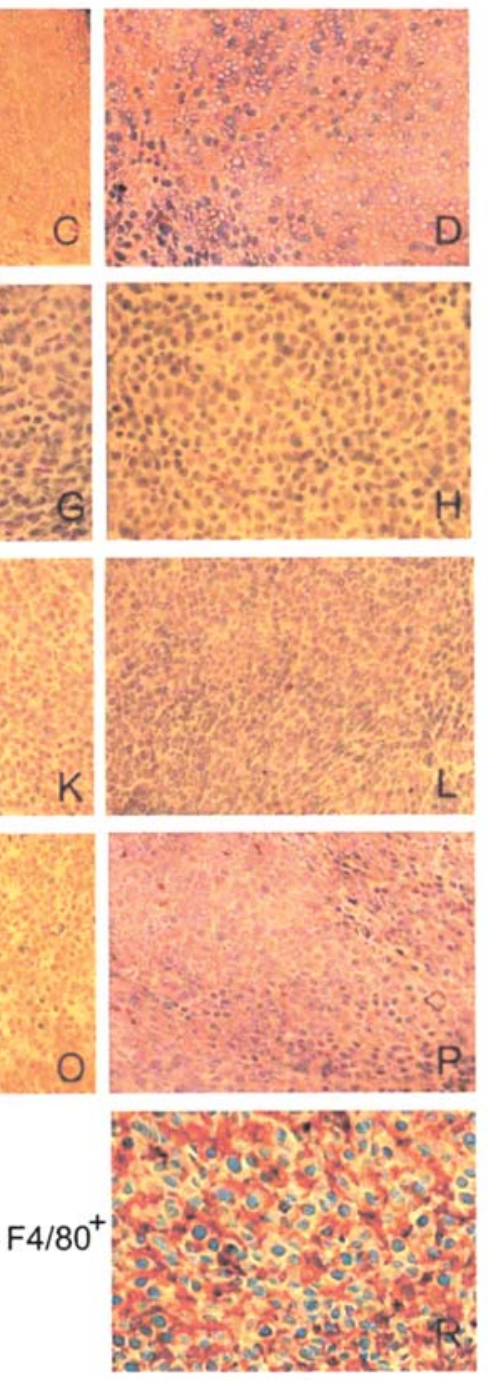

Figure 5. Immunohistochemical staining of leukocytes infiltrating B78-H1 tumors treated with the B78/IL-12 vaccine and/or IL-15. The brownish-red spots reflect cells stained with the anti-CD3 antibody (most likely T lymphocytes) (A-D), anti-CD4 (E-H), anti-CD8 (I-L), anti-Ly6G (anti-Gr1) (granulocytes) (M-P) and anti-F4/80 (macrophages) (R)

vaccine or IL-15 alone showed only occasional curative effects, the combination caused an eradication of established tumors in all the treated mice. The effect of the combined treatment with the B78/IL-12 cells and IL-15 resulted, in part, from Th1-type response, the stimulation of IFN- $\gamma$ production, development of cytotoxic effectors in the spleen and, presumably, from macrophage activation (23). The currently presented results show clearly, that the adjuvant effect of IL-15 is not limited to the IL-12-secreting vaccine. It may also contribute to the increased efficacy of vaccines secreting GM-CSF, TNF- $\alpha$ and IL-6/sIL-6R, being frequently otherwise inefficient. In contrary to cytokine-modified cells, IL-15 does not influence the effect of either empty vectormodified (24) or unmodified irradiated B78-H1 cells (data not shown).

Our findings confirm the previous hypotheses that IL-15 may serve as a universal agent increasing the response to therapeutic tumor vaccines (25). This is due to the unique properties of IL-15. IL-15 influences the innate and acquired arms of the immune response, as it was revealed in this case by immunohistochemical staining. Due to its effects on the proliferation and survival and also the activation and cytotoxicity of NK cells (4), IL-15 can contribute strongly to antitumor immunity. This response can be especially significant in tumors with an aberrant expression of MHC molecules, e.g. in the B78-H1 murine melanoma. Such a situation takes place frequently in case of metastatic lesions and is one of the tumor escape mechanisms. Moreover, IL-15 acts potently on the CD56 $6^{\text {bright }}$ subpopulation of NK cells that, via extensive cytokine secretion, are thought to possess many immunostimulatory functions (4). IL-15 has also been shown to increase cytotoxic antitumor properties of granulocytes (26). The immunohistochemical staining of tumors treated with the B78/IL-12 vaccine in combination with IL-15, unlike those in single-agent treated groups, has shown dramatic infiltration with granulocytes forming dense foci. Moreover, the infiltration with granulocytes was much more pronounced than with $\mathrm{T}$ lymphocytes. B78-H1 tumors contained a large 
proportion of macrophages as shown in Fig. 5R. Treatment with the vaccine and/or IL-15 does not seem to influence their number and appearance (not shown). However, the macrophages isolated from mice treated with the combination of B78/IL-12 and IL-15 secreted significantly higher levels of nitric oxide as compared to other groups (data not shown) that is in compliance with previous observations (27). Therefore, one can speculate that the effect of IL-15 in combination with at least the IL-12 secreting vaccine may depend to a large extent on a nonspecific immune response. In turn, the nonspecific immunological response elicited by IL-15, may facilitate the development of more advanced, specific reactions. Locally secreted cytokines, especially IFN- $\gamma$, strongly induced by IL-15 (5), may increase the expression of antigen presenting molecules on the surface of tumor cells rendering them susceptible to the attack of $\mathrm{T}$ lymphocytes. Simultaneously, IL-15 could enhance antigen presenting properties of specialized antigen presenting cells, both macrophages and dendritic cells and may contribute directly to the presentation of antigens delivered by the vaccine (13).

However, a strong contribution of IL-15 to the effect of vaccinations results probably also from its action on $\mathrm{T}$ lymphocytes. IL-15 is considered to influence the functions of $\mathrm{CD}^{+}$and $\mathrm{CD}^{+} \mathrm{T}$ lymphocytes (28), acting mainly on antigen-activated cells. This was also supported in our study, where IL-15-treated tumors were infiltrated by $\mathrm{CD}^{+}$cells, CD4 and CD8-positive. IL-15 can affect the cytotoxic functions of T cells (12), their cytokine secretion (29), act as a chemotactic factor for them (9) and also inhibit their apoptosis (7). Contrary to IL-2, IL-15 does not contribute to activation-induced cell death (AICD) of lymphocytes during immune response but even inhibits this process (7). Thus, the cytokine-secreting vaccine could act as the source of an antigen and primary activating booster and the elicited response could be further modulated and also persist due to the maintenance of the immunological memory by IL-15 (10). The expansion of the antigen-specific memory of $\mathrm{CD} 8^{+} \mathrm{T}$ cells following the administration of IL-15 could, in a clinical setting, lead to a lower risk of relapse and metastatic disease.

In summary, our study revealed that IL-15 has universal properties of enhancing the effectiveness of whole tumor cell-based vaccines modified with genes encoding different cytokines. IL-15, possessing only moderate antitumor properties, in combination with vaccines that exerted only low or no antitumor activity, resulted in significant inhibition of tumor growth leading to complete tumor eradication in most or even all animals.

\section{Acknowledgements}

This study was supported by the Medical University of Warsaw, Poland, Grant 1M19/W2.

\section{References}

1. Burton JD, Bamford RN, Peters C, Grant AJ, Kurys G, Goldman CK, Brennan J, Roessler E and Waldmann TA: A lymphokine, provisionally designated interleukin $\mathrm{T}$ and produced by a human adult T-cell leukemia line, stimulates T-cell proliferation and the induction of lymphokine-activated killer cells. Proc Natl Acad Sci USA 91: 4935-4939, 1994.
2. Munger W, DeJoy SQ, Jeyaseelan R Sr, Torley LW, Grabstein KH, Eisenmann J, Paxton R, Cox T, Wick MM and Kerwar SS: Studies evaluating the antitumor activity and toxicity of interleukin-15, a new T cell growth factor: comparison with interleukin-2. Cell Immunol 165: 289-293, 1995.

3. Liu CC, Perussia B and Young JD: The emerging role of IL-15 in NK-cell development. Immunol Today 21: 113-116, 2000.

4. Shanmugham LN, Petrarca C, Frydas S, Donelan S, Castellani ML, Boucher W, Madhappan B, Tete S, Falasca K, Conti P and Vecchiet J: IL-15 an immunoregulatory and anti-cancer cytokine. Recent advances. J Exp Clin Cancer Res 25: 529-536, 2006.

5. Carson WE, Ross ME, Baiocchi RA, Marien MJ, Boiani N, Grabstein K and Caligiuri MA: Edogenous production of interleukin 15 by activated human monocytes is critical for optimal production of interferon-gamma by natural killer cells in vitro. J Clin Invest 96: 2578-2582, 1995.

6. Ohteki T, Ho S, Suzuki H, Mak TW and Ohashi PS: Role for IL-15/IL-15 receptor beta-chain in natural killer $1.1^{+} \mathrm{T}$ cell receptor-alpha beta ${ }^{+}$cell development. J Immunol 159: 5931-5935, 1997.

7. Marks-Konczalik J, Dubois S, Losi JM, Sabzevari H, Yamada N, Feigenbaum L, Waldmann TA and Tagaya Y: IL-2-induced activation-induced cell death is inhibited in IL-15 transgenic mice. Proc Natl Acad Sci USA 97: 11445-11450, 2000.

8. Ma A, Koka R and Burkett P: Diverse function of IL-2, IL-15, and IL-7 in lymphoid homeostasis. Annu Rev Immunol 24: 657-679, 2006.

9. Wilkinson PC and Liew FY: Chemoattraction of human blood T lymphocytes by interleukin-15. J Exp Med 181: 1255-1259, 1995.

10. Goldrath AW, Sivakumar PV, Glaccum M, Kennedy MK, Bevan MJ, Benoist C, Mathis D and Butz EA: Cytokine requirements for acute and Basal homeostatic proliferation of naive and memory CD8 ${ }^{+}$T cells. J Exp Med 195: 1515-1522, 2002.

11. Wu TS, Lee JM, Lai YG, Hsu JC, Tsai CY, Lee YH and Liao NS: Reduced expression of Bcl- 2 in $\mathrm{CD}^{+} \mathrm{T}$ cells deficient in the IL-15 receptor alpha-chain. J Immunol 168: 705-712, 2002.

12. Sandau MM, Winstead CJ and Jameson SC: IL-15 is required for sustained lymphopenia-driven proliferation and accumulation of CD8 T cells. J Immunol 179: 120-125, 2007.

13. Dubsky P, Saito H, Leogier M, Dantin C, Connolly JE, Banchereau J and Palucka AK: IL-15-induced human DC efficiently prime malanoma specific naïve $\mathrm{CD} 8^{+} \mathrm{T}$ cells to differentiate into CTL. Eur J Immunol 37: 1678-1690, 2007.

14. Ozdemir O, Ravindranath Y and Savasan S: Mechanisms of superior anti-tumor cytotoxic response of interleukin 15induced lymphokine-activated killer cells. J Immunother 28 : 44-52, 2005.

15. Roychowdhury S, May KF Jr, Tzou KS, Lin T, Bhatt D, Freud AG, Guimond M, Ferketich AK, Liu Y and Caligiuri MA: Failed adoptive immunotherapy with tumor-specific T cells: reversal with low-dose interleukin 15 but not low-dose interleukin 2. Cancer Res 64: 8062-8067, 2004.

16. Meazza R, Lollini PL, Nanni P, De Giovanni C, Gaggero A, Comes A, Cilli M, Di Carlo E, Ferrini S and Musiani P: Gene transfer of a secretable form of IL-15 in murine adenocarcinoma cells: effects on tumorigenicity, metastatic potential and immune response. Int J Cancer 87: 574-581, 2000.

17. Oh S, Berzofsky JA, Burke DS, Waldmann TA and Perera LP: Coadministration of HIV vaccine vectors with vaccinia viruses expressing IL-15 but not IL-2 induces long-lasting cellular immunity. Proc Natl Acad Sci USA 100: 3392-3397, 2003.

18. Umemura M, Nishimura H, Saito K, Yajima T, Matsuzaki G, Mizuno S, Sugawara I and Yoshikai Y: Interleukin-15 as an immune adjuvant to increase the efficacy of Mycobacterium bovis bacillus Calmette-Guerin vaccination. Infect Immun 71: 6045-6048, 2003.

19. Villinger F, Miller R, Mori K, Mayne AE, Bostik P, Sundstrom JB, Sugimoto $C$ and Ansari AA: IL-15 is superior to IL-2 in the generation of long-lived antigen specific memory CD4 and CD8 $\mathrm{T}$ cells in rhesus macaques. Vaccine 22: 3510-3521, 2004.

20. Melchionda F, Fry TJ, Milliron MJ, McKirdy MA, Tagaya Y and Mackall CL: Adjuvant IL-7 or IL-15 overcomes immunodominance and improves survival of the CD8(+) memory cell pool. J Clin Invest 115: 1177-1187, 2005.

21. Lasek W, Mackiewicz A, Czajka A, Switaj T, Golab J, Wiznerowicz M, Korczak-Kowalska G, Balkowiec-Iskra EZ, Gryska K, Izycki D and Jakobisiak M: Antitumor effects of the combination therapy with TNF-alpha gene-modified tumor cells and interleukin 12 in a melanoma model in mice. Cancer Gene Ther 7: 1581-1590, 2000 . 
22. Izycki D, Nawrocki S, Laciak M, Gryska K, Baksalary-Izycka K and Mackiewicz A: Effect of cyclophosphamide on tumorogenesis of the IL-6 and hyper-IL-6 gene modified murine melanoma cells (in polish). Wspólcz Onkol 8: 124-131, 2004.

23. Hoos A, Parmiani G, Hege K, Sznol M, Loibner H, Eggermont A, Urba W, Blumenstein B, Sacks N, Keilholz U and Nichol G: Cancer vaccine clinical trial working group. A clinical development paradigm for cancer vaccines and related biologics. J Immunother 30: 1-15, 2007.

24. Lasek W, Basak G, Switaj T, Jakubowska AB, Wysocki PJ, Mackiewicz A, Drela N, Jalili A, Kaminski R, Kozar K and Jakobisiak M: Complete tumour regressions induced by vaccination with IL-12 gene-transduced tumour cells in combination with IL-15 in a melanoma model in mice. Cancer Immunol Immunother 53: 363-372, 2004.

25. Fehniger TA, Cooper MA and Caligiuri MA: Interleukin-2 and interleukin-15: immunotherapy for cancer. Cytokine Growth Factor Rev 13: 169-183, 2002.
26. Girard D, Paquet ME, Paquin R and Beaulieu AD: Differential effects of interleukin-15 (IL-15) and IL-2 on human neutrophils: modulation of phagocytosis, cytoskeleton rearrangement, gene expression, and apoptosis by IL-15. Blood 88: 3176-3184, 1996.

27. Alleva DG, Kaser SB, Monroy MA, Fenton MJ and Beller DI: IL-15 functions as a potent autocrine regulator of macrophage proinflammatory cytokine production: evidence for differential receptor subunit utilization associated with stimulation or inhibition. J Immunol 159: 2941-2951, 1997.

28. Fehniger TA and Caligiuri MA: Interleukin 15: biology and relevance to human disease. Blood 97: 14-32, 2001.

29. Niedbala W, Wei X and Liew FY: IL-15 induces type 1 and type $2 \mathrm{CD}^{+}$and $\mathrm{CD} 8{ }^{+} \mathrm{T}$ cells proliferation but is unable to drive cytokine production in the absence of TCR activation or IL-12/ IL-4 stimulation in vitro. Eur J Immunol 32: 341-347, 2002. 